\title{
Information Ability Evaluation based on AHP for Students in Police College
}

\author{
Jianying Xiong \\ Security Management Department in Police College of Jiangxi \\ Jiangxi Police Institute \\ Nanchang, China \\ special8212@sohu.com
}

\begin{abstract}
According to the existing Information Literacy assessment system and the information needs of public security, the research has constructed the police information application ability evaluation system. The evaluation system includes three first indicators and can further been subdivided into 10 secondary indicators. Three first indicators are information on general education skills, professional information skills, and innovative information. Analytic Hierarchy Process (AHP) is used to calculate the weight of indicators, and sort them. The comprehensive assessment on information application ability can be calculated by Student Information Evaluation Model in Police Colleges. It is beneficial to assess the quality of higher education, and provide evidence for information ability cultivation of student in police academy.
\end{abstract}

Keywords-Information ability; Police college; Ability evaluation; $\mathrm{AHP}$

\section{INTRODUCTION}

The ability of information began 1970s in the United States. Paul Zurkowski, the President of the American Association for information, use the concept of the information capacity for the first time in 1974 [1]. He supported that a person who can use information resources through training to their work, can be considered to have the information capabilities. Educational Testing Service (ETS) in United States defined the quality of information and communication technology as "In order to meet the community, people have the ability to use digital technology, communication tools, network for acquisition, management, integration, evaluate and create information”. Western countries such as Britain, Australia, the United States, Canada has put forward the concept of Intelligence - led Policing in late 20th century [2]. Both from foreign and domestic experience, Intelligence-led policing can be said that the main direction of police work, but whether it is effective management mechanism, or a high-performance information system will always be part of the information leading police work, the decisive role in people is the most critical. Information Literacy of police officers decided that quality of intelligence-led policing information and the actual job performance [3]. The problem of how to obtain valid information, how to make efficient intelligence analysis of judgments, is the key to lead the public security combat. So the Information literacy of police officers is increasingly becoming prominent issue [4].
Therefore, the police information put forward higher requirements on Information Quality of police officers. The police training school as the main base for police training has put the information ability as the important goals of Police Education and Creative Talents, and as an important part of the public security college students' quality education [5]. Use the students' information ability evaluation combined with academic performance, So as to more effectively measure Police College Students whole information application ability.

\section{THE FACTORS INFLUENCING STUDENTS' INFORMATION ABILITY}

Information ability is the understanding and the application ability of all kinds of information technology, namely, acquisition, understanding, analysis, processing, creation, transfer for information [6-7]. Police information ability refers to the use of certain tools to obtain, and analyze the information they need. It mainly includes the following several aspects. First is the ability to obtain information. In police work in addition to full use of the internal information network organizations access to information, but also good at developing new information resources. Through various channels to obtain information, including the focus of the population, places special industry, the report charged, site surveys and other intelligence information. The second is the information processing capabilities. In order to conduct a comprehensive analysis of the information, the collected information must be filtered and sorted. The third is the ability to use information. Ability to use the information of police is expressed by whether can find online fugitives through comparison. By providing clues to solve judged to combat units; By analyzing the whole situation of public security, warning notification, to provide information for leadership decision-making, etc.

After understanding the concept of Information ability, expand the behavior process of resolving complete information, as shown in Figure 1.

1) Information requirements determination needs.

a) Clearly expressed tasks, projects or information

b) The purpose statement information needs.

c) Determine the source of information based on topic or question form. 
d) Use information about the topics or issues formed structure search strategy.

2) Information retrieval

a) Generate a set of appropriate search terms

b) Determine the need for necessary information

c) According to the information necessary for such purpose, appropriateness, function and form to determine the range of possible sources of information

d) In the search strategy, in accordance with the priority use of the information source

\section{3) Access to information.}

a) The use of different information Retrieval System Retrieval of information in different formats

b) The use of different taxonomies and other system determines find locations

c) The use of specialized sites or face to face service to get information

d) The use of surveys, letters, interviews and other ways to get key information query

4) Information management: the proper way to organize information for subsequent retrieval.

5) Use of information and communication

a) Be able to read information isolated, for information about specific value in meeting the needs of

b) To be effective in information products and results dissemination and exchange

6) Information Restructuring and innovation: the ability to organize information, providing information products.

7) Information Evaluation: Search and compare information from different provenance, Assess the reliability of information, accuracy, authority, timeliness, opinions and prejudices.

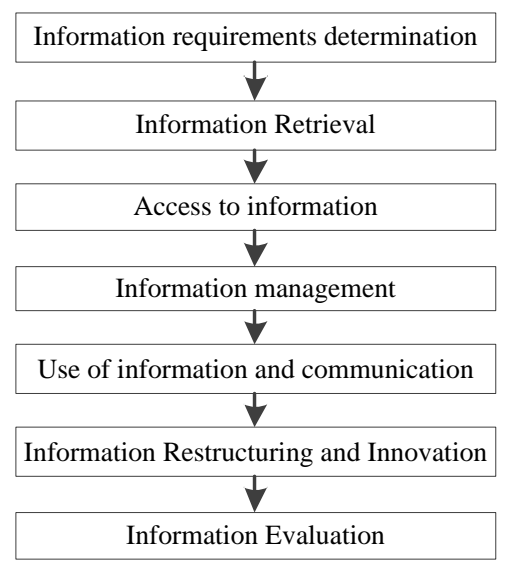

Fig. 1. Behavior process of resolving complete information

\section{AHP EVALUATION MODEL}

\section{A. $A H P$}

The analytic hierarchy process (AHP) is a structured technique for organizing and analyzing complex decisions, based on mathematics and psychology. It was developed by Thomas L. Saaty in the 1970s and has been extensively studied and refined since then. It has particular application in group decision making, [8] and is used around the world in a wide variety of decision situations, in fields such as government, business, industry, healthcare, shipbuilding [9] and education.

\section{B. Evaluation Process}

\section{1) Evaluation factors for AHP structural model}

Combining the present situation of college students' information literacy, in Police College, the information ability can be divided into three levels from lower to higher: general information skills, professional information skills, innovation information skills. This three-level divided into three stages to cultivate. General information skills in foundation Stage includes computer skills, media skills; professional information skills includes ability to determine information needs, ability to retrieval information, ability to obtain information; innovation information skills are subdivided into information reorganization and creativity, information utilization and communication skills, the ability to evaluate information. As shown in Figure 2. The establishment of three information ability assessment model includes three-level information quality indicators, 10 secondary indicators of achievement.

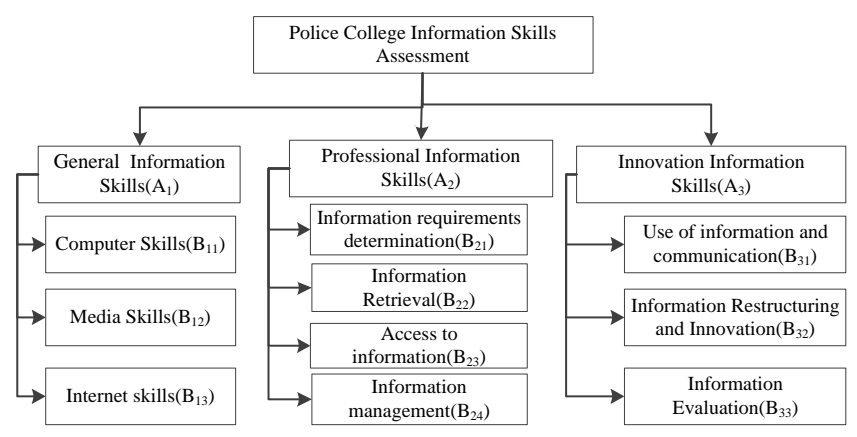

Fig. 2. Information ability assessment model

\section{2) Construction of Evaluation Set}

According to necessary decisions, establish comments set $V$ $=\left\{v_{1}, v_{2}, v_{3}, v_{4}, v_{5}\right\}=\{$ excellent, good, moderate, pass, fail $\}$.

3) Construction of Judgment Matrix

In the first step, the information evaluation factors AHP structural model is established, then the affiliation between the upper and lower levels will be subsequently determined. The next step is to construct the elements of each level fuzzy judgment matrix.

TABLE I. QUANTITY SCALE

\begin{tabular}{ll}
\hline Numeric variables & Linguistic variables \\
\hline 1 & Equal importance \\
3 & Moderate importance \\
5 & Strong importance \\
7 & Very strong importance \\
9 & Extreme importance \\
$2,4,6,8$ & Intermediate values between adjacent scale values \\
If the importance of a and $\mathrm{b}$ is $\mathrm{a}_{\mathrm{ij}}$, the importance of $\mathrm{b}$ and $\mathrm{a}$ is $1 / \mathrm{a}_{\mathrm{ij}}$, \\
\hline
\end{tabular}

Using a quantitative comparison factors and other factors compared to the degree of importance in Pairwise comparison among factors. Then we can get fuzzy judgment matrix. We usually use nine scale methods 1-9 in Table to identify number scale between factors. 
4) The weight calculation

The feature vector $\mathrm{W}$ of elements in judgment matrix $\mathrm{A}$, is the weight of each element. We used $W_{i}$ to express it, and the computation formula is as follow.

$$
w_{i}=\frac{1}{n} \sum_{j=1}^{n} a_{i j}^{*} \quad(i=1,2, \ldots n) \quad \text { where } \quad a_{i j}^{*}=a_{i j} / \sum_{i=1}^{n} a_{i j}
$$

5) The consistency examination of judgment matrix

It should to check the consistency of fuzzy complementary judgment matrix to analyze whether factors importance weight value is reasonable. In this paper, the consistency examination is depending on index of compatibility between fuzzy judgment matrix and its feature matrix. That is to say the consistency index $C I<0.1$

\section{6) Weight sorting}

Sort all elements with respect to the relative importance with target layer, and then we can see clearly which is the most important.

\section{7) Evaluation Method}

We make a comprehensive evaluation of three factors, including general information skills, professional information skills, and innovation information skills. Construct the weight vector $W=\left\{W_{1}, W_{2}, W_{3}\right\}$ by the importance of each factor. The secondary quantization values for respective capabilities is $B=$ $\left\{R_{1}, R_{2}, R_{3}\right\}$; finally we can get a comprehensive assessment of the value $S=W_{1} \times R_{1}+W_{2} \times R_{2}+W_{3} \times R_{3}$.

\section{An Evaluation Case Based on AHP}

STEP 1: According to the information quality assessment factors, the overall ability evaluation system is set as shown in Table 2.

STEP 2: According to the decisions necessary, we establish comments set $V=\left\{v_{1}, v_{2}, v_{3}, v_{4}, v_{5}\right\}=$ \{excellent, good, moderate, pass, fail $\}$, its assignment as $V=\{95,85,75,65,55\}$

STEP 3: Construct comparison matrix and calculate the weight value

The first level index pairwise comparison matrix is constructed according to the Pairwise comparison and comparative scale of 1 to 9 in Table 2. For each pairwise comparison matrix, find each factor weights. "Judgment Matrix" in the pairwise comparison matrix of coincidence detection $C R=0.0011<<0.1$, show that the judgment matrix consistency acceptable;

Secondly, in the same way, we establish second layer of two pairwise comparison matrixes $B_{1}, B_{2}, B_{3}$.

$$
A=\left[\begin{array}{ccc}
1 & 0.25 & 0.5 \\
4 & 1 & 3 \\
2 & 0.33 & 1
\end{array}\right]
$$

"Judgment Matrix" in the pairwise comparison matrices coincidence detection $C R=0.01<0.1$. So $\left\{W_{1}, W_{2}, W_{3}\right\}=\{0.14,0.62,0.24\}$

$$
\mathrm{B}_{1}=\left[\begin{array}{ccc}
1 & 2 & 0.2 \\
0.5 & 1 & 0.2 \\
5 & 5 & 1
\end{array}\right]
$$

Here $\quad C R=0.05<<0.1, \quad$ and $\quad\left\{W B_{11}, \quad W B_{12}\right.$,

$$
B_{2}=\left[\begin{array}{cccc}
1 & 1 & 0.5 & 1 \\
1 & 1 & 0.5 & 1 \\
2 & 2 & 1 & 3 \\
1 & 1 & 0.33 & 1
\end{array}\right]
$$

Here $\quad C R=0.07<<0.1, \quad$ and $\quad\left\{W B_{21}, \quad W B_{22}\right.$, $\left.W B_{23}, W B_{24}\right\}=\{0.2,0.2,0.43,0.17\}$

$$
\mathrm{B}_{3}=\left[\begin{array}{ccc}
1 & 0.2 & 0.33 \\
5 & 1 & 3 \\
3 & 0.33 & 1
\end{array}\right]
$$

Here $C R=0.03<<0.1,\left\{W B_{31}, W B_{32}, W B_{33}\right\}=\{0.11,0.63,0.26\}$

From the final sorting results of combining weights as shown in the table3, the profession people generally believe that professional information skills of the Police College Students is the biggest factor affecting the information ability, and access to information, information retrieval, information requirement determining is more important.

STEP 4: The implementation of the comprehensive evaluation

TABLE II. TABLE STYLES

\begin{tabular}{cccccccc}
\hline $\begin{array}{c}\text { First } \\
\text { level }\end{array}$ & $\begin{array}{c}\text { Second } \\
\text { level }\end{array}$ & \multicolumn{5}{c}{ The judge set membership } & weight \\
excellent & good & moderate & pass & fail & \\
\hline $\mathrm{A}_{1}$ & $\mathrm{~B}_{11}(0.18)$ & 0.4 & 0.5 & 0.1 & 0 & 0 & 0.03 \\
$(0.14)$ & $\mathrm{B}_{12}(0.12)$ & 0.2 & 0.5 & 0.3 & 0 & 0 & 0.02 \\
& $\mathrm{~B}_{13}(0.70)$ & 0.70 & 0.2 & 0.1 & 0 & 0 & 0.1 \\
$\mathrm{~A}_{2}$ & $\mathrm{~B}_{21}(0.2)$ & 0.2 & 0.4 & 0.6 & 0 & 0 & 0.12 \\
$(0.62)$ & $\mathrm{B}_{22}(0.2)$ & 0.2 & 0.6 & 0.2 & 0 & 0 & 0.12 \\
& $\mathrm{~B}_{23}(0.43)$ & 0.4 & 0.4 & 0.2 & 0 & 0 & 0.27 \\
& $\mathrm{~B}_{24}(0.17)$ & 0.2 & 0.6 & 0.2 & 0 & 0 & 0.10 \\
$\mathrm{~A}_{3}$ & $\mathrm{~B}_{31}(0.11)$ & 0. & 0.5 & 0.5 & 0 & 0 & 0.03 \\
$(0.24)$ & $\mathrm{B}_{32}(0.63)$ & 0 & 0.6 & 0.2 & 0.2 & 0 & 0.15 \\
& $\mathrm{~B}_{33}(0.26)$ & 0 & 0.5 & 0.3 & 0.2 & 0 & 0.06 \\
\hline
\end{tabular}

Judging matrix of General information skills for students:

$$
r_{1}=\left[\begin{array}{lllll}
0.4 & 0.5 & 0.1 & 0 & 0 \\
0.2 & 0.5 & 0.3 & 0 & 0 \\
0.7 & 0.2 & 0.1 & 0 & 0
\end{array}\right]
$$

Get expert for comprehensive evaluation of General information skills are as follows:

$$
\begin{aligned}
& \bar{B}_{1}=w_{1}^{T} \mathrm{r}_{1}=\left[\begin{array}{lll}
0.18 & 0.12 & 0.70
\end{array}\right]\left[\begin{array}{ccccc}
0.4 & 0.5 & 0.1 & 0 & 0 \\
0.2 & 0.5 & 0.3 & 0 & 0 \\
0.7 & 0.2 & 0.1 & 0 & 0
\end{array}\right]
\end{aligned}
$$

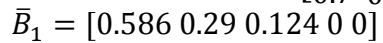

In the same way can get comprehensive evaluation matrix of the other two skills:

Judging matrix of professional information skills:

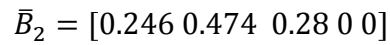

Judging matrix of innovation information skills:

$$
\bar{B}_{3}=\left[\begin{array}{llll}
0 & 0.512 & 0.324 & 0.164
\end{array}\right]
$$

Get comprehensive ability evaluation standards:

$$
\begin{gathered}
A=w^{T} \bar{B} \\
\mathrm{~A}=\left[\begin{array}{lll}
0.14 & 0.62 & 0.24
\end{array}\right]\left[\begin{array}{ccccc}
0.586 & 0.29 & 0.124 & 0 & 0 \\
0.246 & 0.474 & 0.28 & 0 & 0 \\
0 & 0.512 & 0.324 & 0.164 & 0
\end{array}\right] \\
A=\left[\begin{array}{lllll}
0.14 & 0.47 & 0.28 & 0.11 & 0
\end{array}\right]
\end{gathered}
$$

The comprehensive evaluation score of the students' information ability can finally computed by the formula:

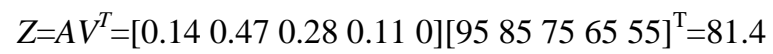




\section{CONCLUSION}

Under conditions of informationization, police Information education should also advance with the times, focusing on ways and means of training students the information ability to explore consciousness and application information. So the graduating students to meet the requirements under the large intelligence information system of public security work. In this paper, the Police College Students' Information Quality Assessment System is based on AHP, which is a multidimensional, multi-level quality assessment model. The Ability level of the student information can be quantified by the model. It is in favor of the Police College Students' information literacy training program and student information application ability examination standards culture.

\section{ACKNOWLEDGMENT}

This research was financially supported by the education department of Education Reform Project, NO. JXJG-15-19-1 in Jiangxi province; and Soft science project, NO. 20161BBA10037 in Jiangxi province.

\section{REFERENCES}

[1] Ukpebor, Christopher O, Mr, and D. Emojorho. "Information Literacy Skills: A Survey of the Transition of Students from Secondary to
University Education in Edo State, Nigeria." Library Philosophy \& Practice (2012).

[2] Peter Bycio, and Joyce S. Allen. "Factors Associated With Performance on the Educational Testing Service (ETS) Major Field Achievement Test in Business (MFAT-B)." Journal of Education for Business 82.4(2007):196-201.

[3] Wang, Zhuo. "Training of digital learning ability of higher vocational students and evaluation criteria integrated information literacy." Journal of Liaoning Administrators College of Police \& Justice (2014).(In Chinese)

[4] Wang, Dong. "To Fully Realize Quality Education in Policemen's Information Literacy-Review and Perspective on the Police Documentary Retrieval Course." Journal of Academic Libraries (2007). (In Chinese)

[5] Sultan M. Al - Daihani, and S. U. Rehman. "A study of the information literacy capabilities of the Kuwaiti police officers." The Electronic Library25.5(2007):613-626.

[6] Zhang, Lipin. "Information Literacy Education in Public Security University Library." Journal of Liaoning Police Academy (2006). (In Chinese)

[7] Kilic, Osman. Information Literacy Skills in the Workplace: A Study of Police Officers. Diss. University of North Texas, 2010.

[8] Kit Fai Pun, Kwai Sang Chin, Man Yin Rebecca Yiu. An AHP approach to assess new product development performance: an exploratory study. International Journal of Management Science \& Engineering Management, 2010, 5(3):210-218.

[9] Saaty, Thomas L. "Decision making the analytic hierarchy and network processes (AHP/ANP)." Journal of Systems Science and Systems Engineering,2014, 13(1):1-35. 